\title{
Correction to: Factors Affecting Construction Labor Productivity: Iran Case Study
}

\author{
Kiyanoosh Golchin Rad ${ }^{1} \cdot$ Soo-Yong Kim ${ }^{1}$
}

Published online: 2 March 2018

(c) Shiraz University 2018

\section{Correction to: Iran J Sci Technol Trans Civ Eng https://doi.org/10.1007/s40996-018-0095-2}

The original version of this article unfortunately contained mistakes. The acknowledgement was missing. It is given below.

\section{Acknowledgements}

The authors would like to express their gratitude to the reviewers for their valuable comments on this paper. This study was supported by a Research Grant of Pukyong National University (2017 year).

The original article can be found online at https:// doi.org/10.1007/s40996-018-0095-2.

\section{Soo-Yong Kim}

kims@pknu.ac.kr

Kiyanoosh Golchin Rad

kiyanoosh@pukyong.ac.kr

1 Department of Civil Engineering, Interdisciplinary Program of Construction Engineering and Management, Pukyong National University, Yongso-ro 45, Nam-gu, Busan 48513, South Korea 